\title{
Metastatic Breast Cancer - Highlights at ASCO 2006
}

\author{
Jens Huober \\ Universitäts-Frauenklinik Tübingen, Germany
}

\section{Key Words}

Breast cancer - Metastases - Trastuzumab resistance . New drugs

\section{Summary}

Several contributions regarding metastatic breast cancer at this year's annual meeting of the American Society of Clinical Oncology (ASCO) were dealing with further optimizing the treatment of HER2-positive patients. Other contributions were concentrating on the improvement of classical treatments, such as chemotherapy or supportive therapies. In a randomized phase III study with anthracyline- and taxane-pretreated HER2-positive patients progressing on trastuzumab (Herceptin ${ }^{\circledR}$ ), the tyrosine kinase inhibitor lapatinib in combination with capecitabine was superior to capecitabine alone. A randomized phase III study of the Arbeitsgemeinschaft Gynäkologische Onkologie (AGO) showed that paclitaxel/capecitabine was as effective as epirubicin/paclitaxel and equally well tolerated in the first-line setting in highrisk metastatic breast cancer patients. In a randomized phase II study in patients with bone metastases, the humanized antibody denosumab proved to be equal to in travenous bisphosphonate therapy. Denosumab was well tolerated, and none of the patients developed antidenosumab antibodies.

\author{
Schlüsselwörter \\ Mammakarzinom - Metastasen . \\ Trastuzumab-Resistenz · Neue Therapien
}

\section{Zusammenfassung}

Wichtige Beiträge zur Behandlung des metastasierten Mammakarzinoms auf der diesjährigen Jahrestagung der Amerikanischen Gesellschaft für Klinische Onkologie (ASCO) beschäftigten sich mit der Verbesserung der Therapie der HER2-positiven Patientin, der Optimierung konventioneller Chemotherapien sowie der Integration neuer supportiver Therapien bei Patientinnen mit Knochenmetastasen. In der HER2-positiven Situation erwies sich der Tyrosinkinasehemmer Lapatinib bei anthrazyklin- und taxanvorbehandelten Patientinnen mit Progression unter Trastuzumab (Herceptin ${ }^{\circledR}$ ) als effektive Substanz und war in einer Phase-III-Studie in Kombination mit Capecitabin der alleinigen Capecitabintherapie signifikant überlegen. In einer randomisierten Phase-IIIStudie der Arbeitsgemeinschaft Gynäkologische Onkologie (AGO) waren Paclitaxel und Capecitabin der anthrazyklinhaltigen Kombination Epirubicin/Paclitaxel in der First-Line-Situation gleichwertig und zeigten ein annehmbares Nebenwirkungsprofil. Der humanisierte Antikörper Denosumab zeigte in einer randomisierten Phase-II-Studie bei Patientinnen mit ossären Metastasen Gleichwertigkeit zur intravenösen Bisphosphonattherapie. Die Behandlung mit Denosumab wurde gut vertragen, Antikörper gegen Denosumab wurden nicht beobachtet.

\begin{tabular}{ll}
\hline KARGER & ( 2006 S. Karger GmbH, Freiburg \\
Fax +497614520714 & Accessible online at: \\
$\begin{array}{l}\text { E-mail Information@Karger.de } \\
\text { www.karger.com }\end{array}$ & www.karger.com/brc
\end{tabular}




\section{Introduction}

Even though metastatic breast cancer is usually incurable, progress has been made in the treatment of this disease, and several interesting contributions were made at this year's annual meeting of the American Society of Clinical Oncology (ASCO), reflecting the continuous research in this field.

The mainstay of the treatment of metastatic breast cancer is systemic therapy. Several options are available, including chemotherapy, endocrine therapy, immunotherapy, and treatment with new agents, such as substances affecting signal transduction pathways or inducing apoptosis. In addition, further improvements regarding supportive therapies are being developed. Since the integration of trastuzumab (Herceptin ${ }^{\circledR}$, Roche Pharma AG, Grenzach-Whylen, Germany) in the therapy of HER2/neu-overexpressing tumors, determination of the HER2/neu receptor is obligatory both in the adjuvant and in the metastatic setting. Only truly HER2-positive patients will benefit from therapy with trastuzumab. It is now obvious that the strategy of treatment of these tumors differs from that of HER2/neu-negative cases, which is why they need to be considered separately.

\section{Chemotherapy}

\section{Non-Anthracaycline versus Anthracyline Combination \\ Therapy}

The German Gynecological Oncology Group (Arbeitsgemeinschaft Gynäkologische Onkologie, AGO) [1] presented a randomized phase III study (AGO MAMMA 3) comparing a non-anthracycline taxane-containing regimen with an anthracycline/taxane regimen in the first-line therapy of metastatic breast cancer. Anthracyclines are highly effective agents in the treatment of metastatic breast cancer and thus are very important in the metastatic setting. Anthracyclinecontaining regimens proved to be more efficacious in the adjuvant treatment of breast cancer than CMF regimens (cyclophosphamide, methotrexate, 5-fluorouracil) and thus have become the standard adjuvant regimen in early breast cancer. Since there is cumulative cardiac toxicity with distinctly increased cardiac toxicity rates for cumulative doses exceeding $450 \mathrm{mg} / \mathrm{m}^{2}$ of doxorubicin or $900 \mathrm{mg} / \mathrm{m}^{2}$ of epirubicin, non-anthracycline-containing combination therapies for highrisk metastatic breast cancer are desirable options. Taxanes are also highly active agents in the treatment of breast cancer, and in a Cochrane analysis the use of taxanes in the metastatic setting showed not only improved disease-free survival in contrast to non-taxane regimens but also better overall survival. For this reason, the combination of epirubicin $\left(60 \mathrm{mg} / \mathrm{m}^{2}\right)$ and paclitaxel $\left(175 \mathrm{mg} / \mathrm{m}^{2}\right)$ was compared to the combination of paclitaxel $\left(175 \mathrm{mg} / \mathrm{m}^{2}\right)$ and capecitabine $\left(2000 \mathrm{mg} / \mathrm{m}^{2}\right)$ - a fluopyrimidine which has shown promising efficacy in anthracycline- and taxane-pretreated patients.
Eligible for enrollment in the study were patients with metastatic breast cancer without prior chemotherapy for metastatic disease. Bone-only disease was not allowed, and patients were required to have adequate hematological, cardiac, hepatic and renal function. Anthracyline pretreatment was allowed up to $360 \mathrm{mg} / \mathrm{m}^{2}$ of epirubicin and $240 \mathrm{mg} / \mathrm{m}^{2}$ of doxorubicin. The aim of this study was to show non-inferiority of paclitaxel/capecitabine (XP, $n=170)$ versus epirubicin/paclitaxel $(\mathrm{EP}, \mathrm{n}=170)$. The primary endpoint was progressionfree survival, secondary endpoints were response rate, overall survival, toxicities, and quality of life in the 2 treatment arms. Baseline characteristics were well balanced between the 2 arms, the median age was 55 and 56 years (range 20-75 years), respectively. Approximately half the patients had at least 2 metastatic sites and predominantly visceral disease. $20 \%$ of the patients had been treated with anthracylines before. Time to disease progression (TTP) was not statistically different between XP and EP treatment (12.0 vs. 11.1 months, respectively). Also, response rates did not differ significantly, with the overall response rate being $52 \%$ in XP-treated patients (complete remission (CR) 7\%, partial remission (PR) $45 \%$ ) and $50 \%$ in EP-treated patients (CR 8\%, PR 43\%). Primary disease progression occurred in $13 \%$ of patients in each treatment arm. The median overall survival was 25.6 (XP) vs. 24.0 months (EP). Both regimens were tolerable and could be administered safely. There were more neutropenias in the EP arm. However, the rate of febrile neutropenia was very low and only slightly increased in EP-treated patients (3 vs. $<1 \%$ ). Skin toxicity and diarrhea were more frequent in the XP arm, but severe (grade3/4) manifestations only occurred in few cases (hand-foot syndrome 12\%, diarrhea 5\%).

In summary, this study shows that XP is an effective treatment in metastatic breast cancer and that the XP regimen is a reasonable non-anthracycline treatment option and treatment alternative to an anthracyline/taxane combination in patients with high-risk metastatic breast cancer.

\section{Chemotherapy in Metastatic HER2/neu-Overexpressing Breast Cancer}

Based on preclinical data which showed synergy between docetaxel, carboplatin and trastuzumab, the Breast Cancer International Research Group (BCIRG) conducted a phase III trial (BCIRG 007) for women with HER2-positive metastatic breast cancer to evaluate the efficacy and safety of trastuzumab in combination with docetaxel or docetaxel and carboplatin [2]. 263 patients with metastatic breast cancer were randomized to either docetaxel $\left(100 \mathrm{mg} / \mathrm{m}^{2}\right)$ or docetaxel $\left(75 \mathrm{mg} / \mathrm{m}^{2}\right)$ and carboplatin (AUC 6) every 3 weeks (q3w) for a maximum of 8 cycles. Trastuzumab was given weekly in the recommended dose. If there was no progression after 8 cycles, trastuzumab was continued ( $\mathrm{q} 3 \mathrm{w}, 6 \mathrm{mg} / \mathrm{kg}$ ) until progression of disease. Primary endpoint was time to progression, secondary endpoints included response rate, duration of response, clinical benefit rate, overall survival and safety. In each 
arm, 131 patients were treated. Patient and tumor characteristics were well balanced between the arms. There was no significant difference between docetaxel/trastuzumab (TH) and docetaxel/carboplatin/trastuzumab (TCH) in median TTP (11.1 vs. 10.4 months), clinical benefit rate (67\% each arm), and duration of response (10.7 vs. 9.4 months). Both regimens could be safely administered. Neutropenic infections were more frequent in the TH arm, thrombocytopenia ( 2 vs. $15 \%$ ), asthenia ( 5 vs. $12 \%$ ), anemia (5 vs. $11 \%$ ) and diarrhea ( 2 vs. $9 \%$ ) were more frequent in the TCH arm.

Hence, the addition of carboplatin did not increase the benefit of the TH regimen as preclinical data had suggested. An explanation might be that the dose of docetaxel, which is the main part of the combination regimen $\mathrm{TCH}$, had to be reduced to $75 \mathrm{mg} / \mathrm{m}^{2}$. Furthermore, only $52 \%$ of the patients received carboplatin at the protocol-specified dose. The combination of docetaxel and trastuzumab is already a very effective regimen in HER2-positive metastatic breast cancer and should not be replaced routinely by the TCH triplet.

\section{HER2-Positive Disease}

Treatment with trastuzumab in combination with chemotherapy or as single treatment is now the standard of care in HER2positive patients with metastatic breast cancer. New studies are currently trying to further optimize the treatment of HER2-positive patients and to find the right strategy for patients progressing on trastuzumab. At this year's ASCO, several presentations dealing with these issues were made. A promising new agent evaluated in these studies is lapatinib, a tyrosine kinase inhibitor of the HER1 and HER2 receptor. In in vitro studies, HER2-positive breast cancer cell lines resistant to trastuzumab were sensitive to lapatinib, and clinical activity was demonstrated for lapatinib in patients with HER2positive breast cancer which progressed on trastuzumab. Moreover, 5-DFUR a metabolite of capecitabine (Xeloda ${ }^{\circledR}$, Roche Pharma AG) demonstrated synergy with lapatinib in breast cancer cell lines.

In order to evaluate the efficacy of lapatinib in trastuzumabresistant breast cancer, a randomized phase III study (EGF 100151) was conducted [3]. Eligible for enrollment were patients with HER2-positive breast cancer with locally advanced or metastatic disease, who had received prior treatment with anthracyclines, taxanes and trastuzumab. The latter had to have been administered for metastatic disease. Patients were randomized to the combination of capecitabine $(2,000$ $\mathrm{mg} / \mathrm{m}^{2} /$ day, days $\left.1-14, \mathrm{q} 3 \mathrm{w}\right)$ and lapatinb $(1,250 \mathrm{mg}$ orally, daily, continuously), or to capecitabine $\left(2,500 \mathrm{mg} / \mathrm{m}^{2} /\right.$ day, days $1-14, \mathrm{q} 3 \mathrm{w}$ ) alone. The primary study endpoint was time to progression, secondary endpoints were overall survival, progression-free survival, overall response, clinical benefit rate and toxicity. As of March 2006, 392 of 528 planned patients had been enrolled. By the time of data lock, 321 patients were included ( $\mathrm{n}=160$ capecitabine/lapatinib, $\mathrm{n}=161$ capecitabine). Patient and tumor characteristics were well balanced, the median age of the study population was 54 (combination) and 51 (single agent) years, half of the patients had at least 3 metastatic sites, and approximately $75 \%$ had visceral disease. The median duration of trastuzumab treatment was 44 weeks, and in about two thirds of the patients the last dose of trastuzumab was given $\leq 8$ weeks prior to randomization. Time to progression was significantly longer with the combination of capecitabine and lapatinib than with capecitabine alone (36.9 vs. 19.7 weeks, $\mathrm{p}=0.00016)$. Overall response was again higher for the combination treatment ( 22.5 vs. $14.4 \%)$. However, this did not reach statistical significance $(\mathrm{p}=0.113)$. So far, the overall survival is similar in both groups, median overall survival has not yet been reached. Fewer patients developed brain metastases as first site of progression in the lapatinib/capecitabine arm. The adverse event rates were similar in both treatment arms for all adverse events as well as severe adverse events. The most frequently observed toxicities (all grades) were diarrhea (55 vs. 39\%), palmoplantar erythema (43 vs. $34 \%$ ), and rash and/or skin reaction (44 vs. 30\%). All toxicities were slightly more frequent with the combination treatment. Severe grade 3 or 4 toxicities were rare. Asymptomatic decline of the left ventricular ejection fraction (LVEF) of $\geq 20 \%$ from baseline to below the lower limit of normal (LLN) occurred in 4 patients in the combination arm and in 1 patient treated with capecitabine alone (unrelated to treatment). There were no symptomatic cardiac events. Based on the data of this planned interim analysis, the independent data monitoring committee recommended to terminate study enrollment because of the clinically meaningful, statistically significant advantage in the primary endpoint TTP in the combination arm versus the chemotherapy-alone arm.

One third of women with HER2-positive metastatic breast cancer develop brain metastases. Trastuzumab, however, does not cross the unaltered blood-brain barrier and is therefore not an effective therapy for brain metastases. Oral tyrosine kinase inhibitors are small molecules and may cross the bloodbrain barrier. For this reason, a study was started to evaluate the safety and efficacy of lapatinib in patients with HER2-positive disease and brain metastases [4]. Eligible patients had HER2-positive breast cancer and at least 1 measurable lesion in the brain. They had progressive metastases of the central nervous system (CNS) after whole brain radiation therapy or asymptomatic brain metastases without prior radiotherapy. Patients received lapatinib $750 \mathrm{mg}$ orally, twice daily. Tumor response was assessed by magnetic resonance imaging (MRI) every 8 weeks. The primary endpoint was objective response (RECIST criteria) in the brain. The 39 enrolled patients were heavily pretreated with at least 3 prior chemotherapy regimens in $70 \%$ of patients. Only $5 \%$ had no prior radiotherapy to the CNS. All patients had developed brain metastases on trastuzumab. 2 patients had a PR, 1 patient achieved a $>30 \%$ response but did not meet RECIST criteria and was excluded 
from the analysis. 5 additional patients had stable disease for $\geq 16$ weeks. Median time to treatment failure was 3.2 months. Preliminary volumetric analysis of 20 of the 39 patients demonstrated 5 patients with $\geq 30 \%$ volumetric decline in CNS lesions and an additional 3 patients with $15-30 \%$ volumetric decline. Of 16 patients with measurable non-CNS disease, 4 showed a PR.

In summary, it can be said that in patients progressing on treatment with trastuzumab, lapatinib in combination with capecitabine was superior to capecitabine alone, and this combination might in future become the standard of care in anthracycline- and taxane-pretreated patients with progression on trastuzumab. Preclinical data suggest that it might also be beneficial to continue trastuzumab, even in the case of progression, and only to change the chemotherapeutic agent. An international multicenter study instigated to answer this question, called 'Treatment beyond Progression' and led by the German Breast Group, is still ongoing. As this important issue has not yet been solved, the best strategy after progression on chemo/trastuzumab combination therapy is not known. Keeping this in mind, we do not know if the chemotherapy-alone option was the 'best comparison' in the EGF 100151 study. Lapatinib could be safely administered in both studies and had an acceptable toxicity profile. Based on preliminary data in patients with CNS metastases demonstrating activity of the drug in these patients, lapatinib will be further explored in this setting.

\section{Supportive Therapy}

Bisphosphonates are standard of care in breast cancer patients with skeletal metastases. Renal toxicity and osteonecrosis of the jaw are toxicities that have been reported with these agents. The receptor activator of NF-kB ligand (RANKL) is a key mediator of osteoclast formation, function and survival. Denosumab, a fully human monoclonal antibody, binds and inhibits RANKL, thus suppressing osteoclastic activity associ- ated with bone metastases. In a phase II study, patients with skeletal metastases without prior bisphophonate therapy [5] were randomized to denosumab in 5 different concentrations and schedules (30 mg q4w, $120 \mathrm{mg} \mathrm{q} 4 \mathrm{w}, 180 \mathrm{mg} \mathrm{q} 4 \mathrm{w}, 60 \mathrm{mg}$ q12w, $180 \mathrm{mg}$ q12w; double blind) or to bisphosphponate therapy (open label). Primary endpoint was the percentage change from baseline to week 13 in the resorption marker urinary N-telopeptide. Other endpoints were the percentage of patients with $\geq 1$ skeletal related event (SRE) and safety. In total, 255 patients were enrolled, most patients had $>2$ sites of bone metastases. The $120 \mathrm{mg} \mathrm{q} 4 \mathrm{w}$ dose resulted in the greatest decrease (\%) from baseline of N-telopeptide (-82 vs. $-71 \%$ for $30 \mathrm{mg}$ and $180 \mathrm{mg} \mathrm{q} 4 \mathrm{w}$ or $\mathrm{q} 12 \mathrm{w}$, and $63 \%$ for $60 \mathrm{mg}$ ). The number of patients with at least 1 SRE was $9 \%$ (20/212) for all denosumab-treated patients and 16\% (7/43) in bisphosphonate-treated patients. Denosumab was well tolerated, of 198 tested patients none developed anti-denosumab antibodies. In this phase II study, denosumab given subcutaneously was at least as effective as intravenous bisphosphonate therapy and could be safely administered. A phase III study has been started comparing zoledronate with denosumab $120 \mathrm{mg}$ q4w.

\section{Conclusions}

The contributions at this year's ASCO regarding metastatic breast cancer are reflecting the progress made in this field both through the integration of new agents in clinical routine and further improvement of classical treatments and supportive therapies. In high-risk metastatic breast cancer, the combination of capecitabine and paclitaxel proved to be an effective non-anthracycline first-line treatment option. In HER2-positive disease, it appears that the tyrosine kinase inhibitor lapatinib is efficacious even in trastuzumab-resistant cases and in patients with brain metastases. For patients with bone metastases, the antibody denosumab may in future be an alternative to bisphosphonates, with a different toxicity pattern.

\section{References}

1 Lück H, von Minkwitz G, duBois A, et al.: Epirubicin/paclitaxel vs. capecitabine/paclitaxel in first line metastatic breast cancer: a prospective, randomized multicentre phase III study of the AGO breast cancer study group. Proc ASCO 2006;24: abstr 517.

2 Forbes J, Kennedy T, Pienkowski T, et al.: BCIRG 007: randomized phase III trial of trastuzumab plus docetaxel with or without carboplatin first line in her 2 positive metastatic breast cancer: main time to progression analysis. Proc ASCO 2006;24:abstr 516.
3 Geyer CE, Cameron D, Lindquist D, et al.: A phase III randomized open label international study comparing lapatinib and capecitabine vs. capecitabine in women with refractory advanced or metastatic breast cancer. Scientific special session: lapatinib in trastuzumab resistant breast cancer. ASCO 2006, special session

4 Lin UN, Carey LA, Liu MC, et al.: Phase II trial of lapatinib for brain metastases in patients with her2+ breast cancer. Proc ASCO 2006;24:abstr 503.

\footnotetext{
5 Lipton A, Alvarado R, de Boer R, et al.: Randomized active-controlled study of denosumab (AMG 162 ) in breast cancer patients with bone metastases not previously treated with intravenous bisphosphonates. Proc ASCO 2006;24:abstr 512
} 